\title{
Gene flaw found in induced stem cells
}

Stem-cell researchers have puzzled over why reprogrammed cells taken from adult tissues are often slower to divide and much less robust than their embryo-derived counterparts.

Now, a team has discovered the key genetic difference between embryonic and adult-derived stem cells in mice. If confirmed in humans, the finding could help clinicians to select only the heartiest stem cells for therapeutic applications and disease modelling.

Induced pluripotent stem (iPS) cells are created by reprogramming adult cells, and outwardly seem indistinguishable from embryonic stem (ES) cells. Both cell types are pluripotent - they can form any tissue in the body.

Yet subtle distinctions abound. Last month, for example, Su-Chun Zhang and his colleagues at the University of WisconsinMadison compared the ability of both types of pluripotent cell to form human neurons in a laboratory setting, and found that iPS cells did so with markedly lower efficiency than ES cells (B.-Y. Hu et al. Proc. Natl Acad. Sci. USA 107, 4335-4340; 2010).

Last year, researchers also reported consistent differences in gene expression between the two cell types (M. H. Chin et al. Cell Stem Cell 5, 111-123; 2009). However, because scientists have always obtained iPS and ES cells from different sources - in general, iPS cells are derived from skin samples taken during biopsies and ES cells from excess embryos from fertility clinics - it was impossible to tell whether the discrepancies could be chalked up to the unique biology of the cells or the genetics of the underlying tissue.

\section{Silence please}

A team led by Konrad Hochedlinger at Massachusetts General Hospital in Boston has now derived iPS and ES cells with identical DNA. The iPS cells were less efficient than the ES cells at incorporating into chimeric mice - a standard test of pluripotency, or 'stemness'. The team added the stem cells into embryos from mice of a different colour; once each mouse matures, the colouring of its coat reveals how much the stem cells contributed to forming its tissue.

When the scientists compared genome-wide expression patterns between the two cell types, they discovered that a small stretch of DNA on the long arm of chromosome 12 displayed significantly different gene activity. In this region, two genes and a slew of tiny regulatory sequences called microRNAs were consistently activated in the ES cells and silenced in the iPS cells, regardless of whether the reprogrammed cells came originally from skin, brain, blood or other tissue. Although the function of the key genes is unknown, this region is usually

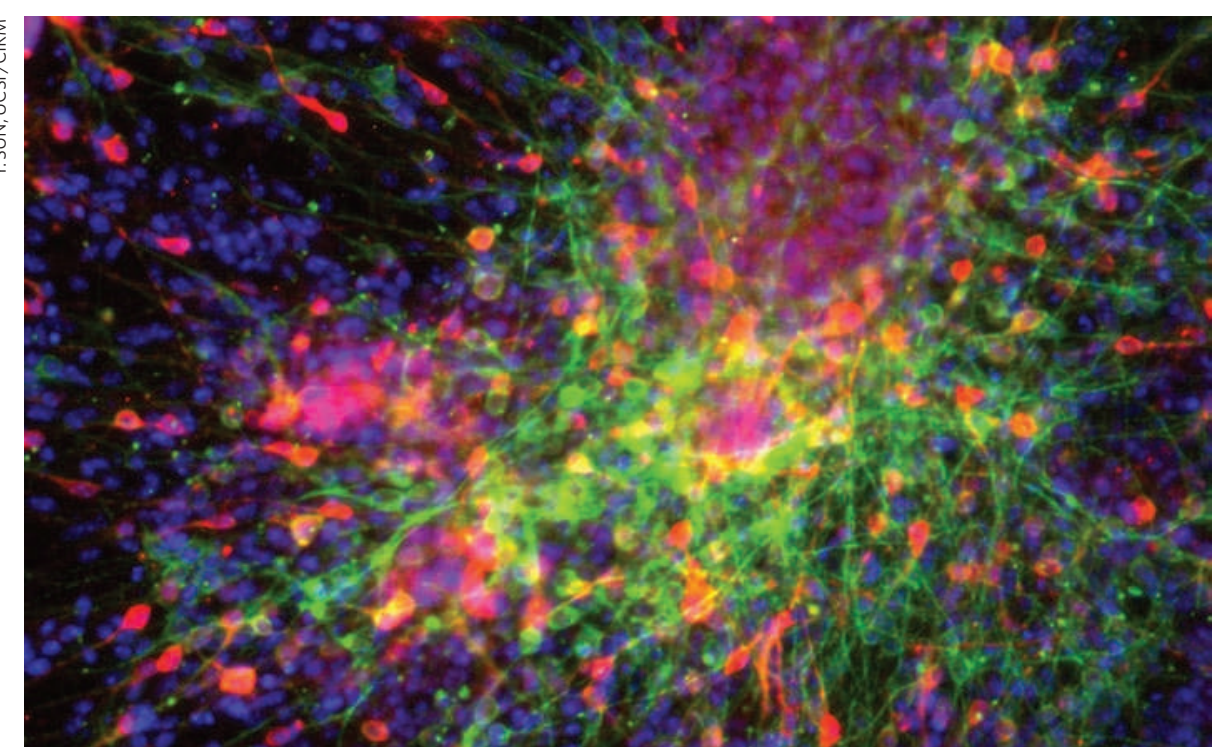

Mouse stem cells can be used to create neurons (above) for the screening of drugs.

silenced in mouse sperm cells and activated in other types of cell, so reprogramming might somehow mimic the silencing process, the authors speculate.

"This is an important step towards identifying the differences that may exist in those imperfectly reprogrammed cells,' says Sheng Ding, a stem-cell researcher at the Scripps Research Institute in La Jolla, California.

The discovery raises the possibility that human iPS cells carry similar silenced sequences that make them less effective than ES cells, according to team member Matthias Stadtfeld, also from the Massachusetts General Hospital, who presented the work at a meeting of the New York Academy of Sciences on 23 March. "It points towards the possibility that hot spots for epigenetic abnormalities exist also in human iPS

s. "A profound abnormality like that could confound results obtained with patient-specific iPS cells."

John Hambor, director of stem-cell-based drug discovery at Cell Therapy Group, a consultancy based in Madison, Connecticut, cautions that although the iPS cells in the experiment did not meet the strictest criteria of stemness - they did not introduce significant colouring into chimeric mice they may still have been able to form many types of tissue, something the researchers did not explicitly test. Stadtfeld agrees, noting that the silenced genes "might not matter for tissues in which [such] genes have no role".

Although findings in mice don't always apply to humans, if a similar gene signature is found in human cells, it could help researchers to identify which iPS cells to avoid using, and which stand the best chance of producing the desired tissue. Hochedlinger's team has therefore begun to look at human ES and iPS cells in search of similar gene-activity patterns to those they found in mice.

Elie Dolgin

\section{Correction}

A News Briefing (Nature 464, 330; 2010) wrongly stated that the Intergovernmental Panel on Climate Change had appointed the InterAcademy Council to review its procedures. The council was invited by the United Nations and the World Meteorological Organization to conduct the review. 